\title{
Analysis of Milk Production Traits in Early Lactation Using a Reaction Norm Model with Unknown Covariates
}

\author{
M. M. Shariati, ${ }^{*}+\ddagger^{1}$ G. Su, ${ }^{*}$ P. Madsen, ${ }^{*}$ and D. Sorensen ${ }^{*}$ \\ *Department of Genetics and Biotechnology, Faculty of Agricultural Sciences, University of Aarhus, PO Box 50, DK-8830 Tjele, Denmark \\ †Department of Large Animal Sciences, Faculty of Life Sciences, University of Copenhagen, Ridebanevej 12, DK-1870 Frederiksberg C, \\ Denmark \\ ‡Department of Animal Science, Ferdowsi University of Mashhad, 91775-116 Mashhad, Iran
}

\begin{abstract}
The reaction norm model is becoming a popular approach to study genotype $\times$ environment interaction $(\mathrm{G} \times \mathrm{E})$, especially when there is a continuum of environmental effects. These effects are typically unknown, and an approximation that is used in the literature is to replace them by the phenotypic means of each environment. It has been shown that this method results in poor inferences and that a more satisfactory alternative is to infer environmental effects jointly with the other parameters of the model. Such a reaction norm model with unknown covariates and heterogeneous residual variances across herds was fitted to milk, protein, and fat yield of first-lactation Danish Holstein cows to investigate the presence of $\mathrm{G} \times \mathrm{E}$. Data included 188,502 first test-day records from 299 herds and 3,775 herd-years in a time period ranging from 1991 to 2003. Variance components and breeding values were estimated with a Bayesian approach implemented using Markov chain Monte Carlo. The posterior distribution of the variance of genetic slopes was markedly shifted away from zero for all traits under study, supporting the presence of $\mathrm{G} \times \mathrm{E}$. The ratio of the genetic slope variance to the genetic level variance was highest for fat yield, followed by protein and milk yields. Genetic correlations between environments that differ by plus and minus 1 standard deviation from the mean environmental effect were $0.93,0.91$, and 0.89 for milk, protein, and fat yield, respectively. Genetic variances and heritabilities increased with increasing level of environmental effects. The rank correlations between predicted breeding values at the 5th and 95th percentiles of the distribution of environmental effects were, respectively, equal to $0.91,0.90$, and 0.76 , for milk, protein, and fat yield. Thus in this study, although $\mathrm{G} \times \mathrm{E}$
\end{abstract}

Received January 23, 2007.

Accepted September 4, 2007.

${ }^{1}$ Corresponding author: mohammad.shariati@agrsci.dk was detected, it has a small effect on reranking of candidates for selection.

Key words: reaction norm, unknown covariate, residual variance heterogeneity, herd-year environment

\section{INTRODUCTION}

In quantitative genetics the presence of genotype $x$ environment interaction $(\mathbf{G} \times \mathbf{E})$ is investigated by introducing random genotype $\times$ environment interaction effects in a linear model, using multitrait models, or using reaction norm models (Falconer and MacKay, 1996; Lynch and Walsh, 1998). In the first case, the presence of $\mathrm{G} \times \mathrm{E}$ is detected by a significant variance component associated with the distribution of the interaction effects. In the multitrait model, one trait measured in several environments is considered to be a different trait within each environment. High genetic correlations (close to 1) between traits indicate that the same set of genes operates in the different environments and no genotype by environment interaction is detected. Lower genetic correlations ( $<0.8$; Robertson, 1959) imply that partly different genes control the trait in the different environments, indicating the presence of genotype $\times$ environment interaction. This approach is difficult to apply if there is a gradient of effects over a large number of environments. Strandberg (2006) provides a review of methods used to investigate $\mathrm{G} \times \mathrm{E}$ in animal breeding.

The reaction norm model is an interesting alternative to the multiple trait approach because it can accommodate a large number of environmental levels with few parameters. It assumes that the response variable is linearly related to the covariate representing the environmental variable. The slope associated with a given individual is a measure of its environmental sensitivity, and the amount of variation in slope in the population indicates the degree of $\mathrm{G} \times \mathrm{E}$ that exists for the trait under consideration. Linear reaction norms have usually been used to detect $\mathrm{G} \times \mathrm{E}$ because they are simple to interpret (Kolmodin et al., 2002; Calus and Veerkamp, 2003; Oseni et al., 2004). 
In the reaction norm model the value of the covariate is typically unknown, and an approximation used in the literature consists of replacing the covariate by the average phenotypic performance of the individuals in a given environment [e.g., herd-year (Kolmodin et al., 2002; Fikse et al., 2003; Hayes et al., 2003)]. Other suggestions are to estimate herd(-year) effects in a standard additive genetic model and to use these as proxies for the unknown covariates in the reaction norm model (Calus et al., 2002; Oseni et al., 2004), or using the reaction norm model, to replace the covariates by estimates obtained in an iterative manner (Calus et al., 2004). These methods have a number of shortcomings, especially when the trait of interest is under selection (Calus et al., 2004; Su et al., 2006). Su et al. (2006) developed a Bayesian reaction norm model for inferring genetic parameters and environmental covariates simultaneously. The advantage of this approach over the approximate methods was shown in a simulation study (Su et al., 2006).

Several studies have reported the presence of $\mathrm{G} \times \mathrm{E}$ in milk production traits using approximate methods (Kolmodin et al., 2002; Calus and Veerkamp, 2003; Hayes et al., 2003). The aim of this study is to apply the methodology proposed by Su et al. (2006) to investigate the magnitude of $\mathrm{G} \times \mathrm{E}$ for dairy production traits (milk, protein, and fat yield) in early lactation using a random regression model where covariates (herd-years) are treated as unknown and inferred jointly with the remaining parameters. In this study the model was also extended to account for heterogeneity of within herd residual variance.

\section{MATERIALS AND METHODS}

\section{Data}

Data were extracted from the Danish national cattle database (Bundgaard and $\mathrm{H} \varnothing \mathrm{j}, 2000$ ) and consisted of the first test-day records for milk, protein, and fat of first-lactation Danish Holstein cows having their first calving in the period between 1991 and 2003. Only records in the interval 10 to $50 \mathrm{~d}$ postpartum and belonging to a herd with at least 30 first-lactation cows per year were included in the analysis. Compared with other analyses, this is much higher than the minimum of 3 (Calus et al., 2002; Raffrenato et al., 2003) and 4 to 5 (Calus and Veerkamp, 2003) records considered in each environment. The requirement of at least 30 cows per herd-year was imposed to ensure that enough information was available to estimate herd-year effects and the variance of herd-year effects. The final data set included 188,502 first test-day records from 299 herds. A pedigree file was built by tracing the 188,502 cows as far back as possible in the Danish national cattle database. The traced pedigree file consisted of 358,038 individuals. Table 1 shows descriptive statistics of the data.

This first application of a linear reaction norm model with unknown covariates on field data was based on first test-day records for the following reasons:

1. Model simplicity by not having repeated records on each cow. Repeated records would require an additional random permanent environmental effect for each cow with data, and both the genetic and permanent environmental effects should be modeled by some function to describe the longitudinal nature of the traits.

2. To avoid selection bias from using 305-d records, which requires either that the cow completes the 305-d lactation or that extended 305-d lactation records are used for cows not completing the 305d lactation.

\section{Statistical Model}

Sampling Model. The linear reaction norm model used to analyze the data was

$$
\begin{gathered}
y_{i j k l m p}=f_{j}+d m_{k}+a g e_{l}+c y_{m}+r(h e t) \\
+s(\text { prop })+a_{0_{i}}+a_{f_{i}} f_{j}+e_{i j k l m p},
\end{gathered}
$$

where $y_{i j k l m p}$ is the first test-day record for milk, protein, or fat from the $i$ th animal in the $j$ th herd-year, $k$ th DIM, $l$ th age at calving, $m$ th calving year, and $p$ th residual variance group (herd); $f_{j}$ is the random effect of the $j$ th herd-year (3,775 classes); $d m_{k}$ is the fixed effect of the $k$ th DIM (41 classes); age $e_{l}$ is the fixed effect of the $l$ th age at calving in months (22 classes); $c y_{\mathrm{m}}$ is the fixed effect of the $m$ th year of calving (14 classes); het is the breed heterozygosity; $r$ is the regression on breed heterozygosity; prop is the proportion of Holstein Friesian genes; $s$ is the regression on the proportion of Holstein genes; $a_{0 i}$ is the additive genetic level of the $i$ th animal; $a_{f i}$ is the regression on the unknown herdyear effect specific to animal $i$; and $e_{i j k l m p}$ is the residual effect. Herd-year effects were treated as random effects because the model with fixed environmental effects is not identifiable. It has been shown that treating herdyear effects as random can increase the accuracy of selection (Visscher and Goddard, 1993) and the predictive ability of the model (Babot et al., 2003). Because herd-year effects were treated as random, calving year was included in the model as a fixed effect to account for the effect of environmental time trend (Babot et al., 2003).

When there is an association between sire effects and herd effects, treating herd-year effects as random can 
Table 1. Descriptive statistics of the data

\begin{tabular}{lcccr}
\hline Item & Mean & Minimum & Maximum & SD \\
\hline Milk (kg) & 24.77 & 1.50 & 60.70 & 5.32 \\
Protein (kg) & 0.77 & 0.05 & 2.07 & 0.16 \\
Fat (kg) & 1.04 & 0.03 & 3.86 & 0.26 \\
Proportion of Holstein genes & 0.77 & 0.30 & 1 & 0.16 \\
Heterozygosity & 0.30 & 0.01 & 1 & 0.13 \\
Days in milk & 26.18 & 10 & 50 & 3.20 \\
Age at calving (mo) & 27.56 & 18 & 213 & 3.30 \\
Records in each herd-year & 53 & 30 & & 21 \\
\hline
\end{tabular}

lead to biased estimates of breeding values (Henderson, 1973). Visscher and Goddard (1993) found a substantial bias under negative association of sires and herd environments for all contemporary group sizes. Inclusion of the relationship among animals using an animal model can decrease this possible bias (Ugarte et al., 1992). Ugarte et al. (1992), in a simulation study with preferential use of sires across herds, found that there was no bias in predicted breeding values in scenarios where sizes of contemporary groups were larger than 12 . This was under positive association between sires and herds, which is expected to be the case for production traits.

The sampling distribution of the observations was

$$
\begin{gathered}
\mathbf{y} \mid \mathbf{b}, \mathbf{f}, \mathbf{a}_{0}, \mathbf{a}_{\mathbf{f}} \sim \mathrm{N}\left(\mathbf{X b}+\mathbf{E f}+\mathbf{Z} \mathbf{a}_{0}\right. \\
\left.+\mathrm{Z}_{f} \mathrm{a}_{f}, \operatorname{Var}(\mathbf{e})\right),
\end{gathered}
$$

where $\mathbf{b}$ is a vector containing effects of DIM, age at calving, calving year, regressions on breed heterozygosity and proportion of Holstein Friesian genes; $\mathbf{f}$ is the vector of herd-year effects; $\mathbf{a}_{0}$ and $\mathbf{a}_{\mathrm{f}}$ are the vectors of genetic levels and slopes, respectively; $\mathbf{X}, \mathbf{E}$, and $\mathbf{Z}$ are known incidence matrices; and $\mathbf{Z}_{f}$ is the unknown incidence matrix constructed with elements using $\mathbf{f}$ to associate the genetic slopes to the records. The (co)variance structure of the model is

$$
\operatorname{Var}\left[\begin{array}{c}
\mathbf{a}_{0} \\
\mathbf{a}_{f} \\
\mathbf{f} \\
\mathbf{e}
\end{array}\right]=\left[\begin{array}{ccccc}
\mathbf{G} \otimes & \mathbf{A} & \mathbf{0} & \mathbf{0} \\
& \mathbf{0} & \mathbf{0} \\
\mathbf{0} & \mathbf{0} & \mathbf{I} \sigma_{f}^{2} & \mathbf{0} \\
\mathbf{0} & \mathbf{0} & \mathbf{0} & \mathbf{D}
\end{array}\right],
$$

where $\mathbf{G}=\left[\begin{array}{cc}\sigma_{a_{0}}^{2} & \sigma_{a_{0} a_{f}} \\ \sigma_{a_{0} a_{f}} & \sigma_{a_{f}}^{2}\end{array}\right]$ is the (co)variance matrix of genetic level and slope, $\mathbf{A}$ is the additive genetic relationship matrix of all animals in the pedigree, $\mathbf{I}$ is the identity matrix, and $\sigma_{f}^{2}$ is the variance of herd-year effects. Heterogeneity of residual variation (Short et al., 1990; Ibanez et al., 1999) was taken into account by postulating a residual variance peculiar to each of the 299 herds in the data set. Therefore $\mathbf{D}=\operatorname{diag}\left(\sigma_{e_{p}}^{2}\right), P=1,2, \ldots$, 299 , is a diagonal matrix with herd specific residual variances on the diagonal. Heterogeneity at the level of herd-years could not be ascertained due to numerical instability of the algorithm, presumably due to the large number of residual variance parameters in relation to the number of observations per herd-year.

Prior Distributions. The vector $\mathbf{b}$ was assumed to have an improper prior distribution. The prior distributions of genetic levels and slopes as well as herd effects were assumed to be normal with mean equal to zero and with a (co)variance matrix defined in [2]. Scaled inverted $\chi^{2}$ distributions were considered for the variance component of herd effects $\left(\sigma_{f}^{2}\right)$ and for the elements of $\mathbf{D}$, and finally, an inverse Wishart distribution was specified for $\mathbf{G}$.

Joint Posterior Distribution. The joint posterior distribution of all parameters was

$$
\begin{gathered}
p\left(\boldsymbol{\theta}, \mathbf{f}, \mathbf{G}, \sigma_{f}^{2}, \mathbf{D} \mid \mathbf{y}\right) \\
\propto p(\mathbf{y} \mid \boldsymbol{\theta}, \mathbf{f}, \mathbf{D}) p\left(\mathbf{f} \mid \sigma_{f}^{2}\right) p\left(\sigma_{f}^{2}\right) p\left(\mathbf{a}_{0}, \mathbf{a}_{f} \mid \mathbf{G}\right) p(\mathbf{G}) p(\mathbf{D}),
\end{gathered}
$$

where $\boldsymbol{\theta}=\left\{\mathbf{b}, \mathbf{a}_{0}, \mathbf{a}_{f}\right\}$ is the vector of location parameters.

In this model the breeding value of individual $i$ in environment $j$ was given by

$$
a_{i j}=a_{0 i}+a_{f i} f_{j}
$$

The genetic variance in environment $f_{\mathrm{j}}$ was defined as

$$
\sigma_{a(j)}^{2}=\sigma_{a_{0}}^{2}+f_{j}^{2} \sigma_{a_{f}}^{2}+2 f_{j} \sigma_{a_{0} a_{f}}
$$

The heritability in herd-year $f_{\mathrm{j}}$ was defined as

$$
h_{j p}^{2}=\frac{\sigma_{a(j)}^{2}}{\sigma_{a j)}^{2}+\sigma_{e_{p}}^{2}},
$$

where $\sigma_{a(j)}^{2}$ is defined in [4] and $\sigma_{e_{p}}^{2}$ is the residual variance in herd $p$. 
The genetic covariance between environments $f_{i}$ and $f_{j}$ is defined as

$$
\sigma_{a_{i j}}=\sigma_{a_{0}}^{2}+f_{i} f_{j} \sigma_{a_{f}}^{2}+\left(f_{i}+f_{j}\right) \sigma_{a_{0} a_{f}},
$$

and the genetic correlation between environments $f_{i}$ and $f_{j}$ is

$$
r_{a_{i j}}=\frac{\sigma_{a_{i j}}}{\sigma_{a(i)} \sigma_{a(j)}} .
$$

If the slope is the same for all individuals, $\sigma_{a_{f}}^{2}=$ $\sigma_{a_{0} a_{f}}=0$, and $r_{a_{i j}}=1$, indicating absence of $\mathrm{G} \times \mathrm{E}$. Hereinafter, for each trait estimated herd-year effects $\mathbf{f}$ have been expressed in units of their standard deviation, yielding standardized herd-year effects $\mathbf{f}^{*}=\mathbf{f} / \sigma_{f}^{2}$. As a result, genetic slope variances and covariances between level, slope, and heritabilities have been transformed accordingly, as shown by Su et al. (2006).

\section{Model Comparison}

The linear reaction norm model with unknown covariates with herd specific residual variances (RNUCH) was compared with a reaction norm model with homogeneous residual variance (RNUCS) and to an animal model with herd specific residual variances but without random regressions (ANH). The deviance information criterion (DIC) was used as the criterion of comparison. Let $\theta$ represent parameters of a model. The DIC is computed as

$$
D I C=\bar{D}(\theta)+P_{D(\bar{\theta})}
$$

where $\bar{D}(\theta)$ is the posterior mean of the deviance that is $-2 \log p(y \mid \theta)$. The effective number of parameters $P_{D(\bar{\theta})}$ is determined by $P_{D(\bar{\theta})}=\bar{D}(\theta)-D(\bar{\theta})$, where $\bar{\theta}$ is the posterior mean of $\theta$. Smaller quantities of DIC indicate a better fit, after penalization for model complexity (Spiegelhalter et al., 2002).

\section{Implementation of the Gibbs Sampler}

In the Gibbs sampler the parameters were updated from their fully conditional posterior distributions that can be derived from the joint posterior distribution in [3] (Sorensen and Gianola, 2002). In the Bayesian setting of the linear reaction norm model with unknown covariates, all the fully conditional distributions are of standard form and are given in Su et al. (2006).

Post Gibbs analysis of MCMC output from previous analyses of the present data with slightly different mod-
Table 2. Estimated Monte Carlo standard errors $\left(\mathrm{MCSE} \times 10^{3}\right)$ and effective chain sizes of chosen parameters of the reaction norm model with unknown covariates and herd-specific residual variances ${ }^{1}$

\begin{tabular}{lllll}
\hline Item & $\sigma_{a_{0}}^{2}$ & $\sigma_{a_{0} a_{f}}$ & $\sigma_{a_{f}}^{2}$ & $\sigma_{f}^{2}$ \\
\hline MCSE & & & & \\
$\quad$ Milk & 7.82 & 9.00 & 10.11 & 24.97 \\
$\quad$ Protein & 0.0070 & 0.0090 & 0.0064 & 0.0243 \\
$\quad$ Fat & 0.0244 & 0.0165 & 0.0220 & 0.0550 \\
Effective size & & & & \\
$\quad$ Milk & 267 & 57 & 30 & 60 \\
$\quad$ Protein & 308 & 52 & 38 & 81 \\
Fat & 189 & 129 & 60 & 87 \\
\hline
\end{tabular}

${ }^{1}$ The lengths of MCMC chains are 200,000 for milk and fat, and 300,000 for protein yield.

els indicated that an adequate strategy in terms of Monte Carlo standard errors was to execute the sampler using a burn in of length 100,000 followed by a chain of length 200,000 for milk and fat yield. Rate of convergence and effective chain length was smaller for protein yield; therefore, 200,000 iterations of the Gibbs sampler were considered as burn-in followed by a chain of length 300,000. Monte Carlo standard errors and effective chain sizes of the MCMC output of RNUCH have been displayed in Table 2 .

\section{RESULTS AND DISCUSSION}

\section{Model Comparison}

For milk and protein yield, RNUCH showed the smallest DIC, followed by ANH and RNUCS (Table 3). This justifies the inclusion of random genetic slopes and herd specific residual variances in the model, despite the larger number of parameters. For fat yield, however, using RNUCS led to the smallest DIC followed by RNUCH and ANH, although the difference between DIC of RNUCS and RNUCH was small. Further, using RNUCS for analyzing fat yield, the variance of genetic slope became very high and the genetic correlation between poor and good environments was negative at the extremes (not shown). In the same manner, using RNUCS for analyzing milk and protein yield, the genetic correlation between environments was underesti-

Table 3. Deviance information criterion of additive genetic model with herd specific residual variance $(\mathrm{ANH})$, reaction norm model with unknown covariates and single residual variance (RNUCS), and reaction norm model with unknown covariates and herd specific residual variance (RNUCH) for milk, protein, and fat yield

\begin{tabular}{lcrr}
\hline Item & ANH & RNUCS & RNUCH \\
\hline Milk & $1,095,700$ & $1,096,916$ & $1,094,714$ \\
Protein & $-212,956$ & $-211,262$ & $-214,341$ \\
Fat & $-28,793$ & $-37,230$ & $-36,524$ \\
\hline
\end{tabular}



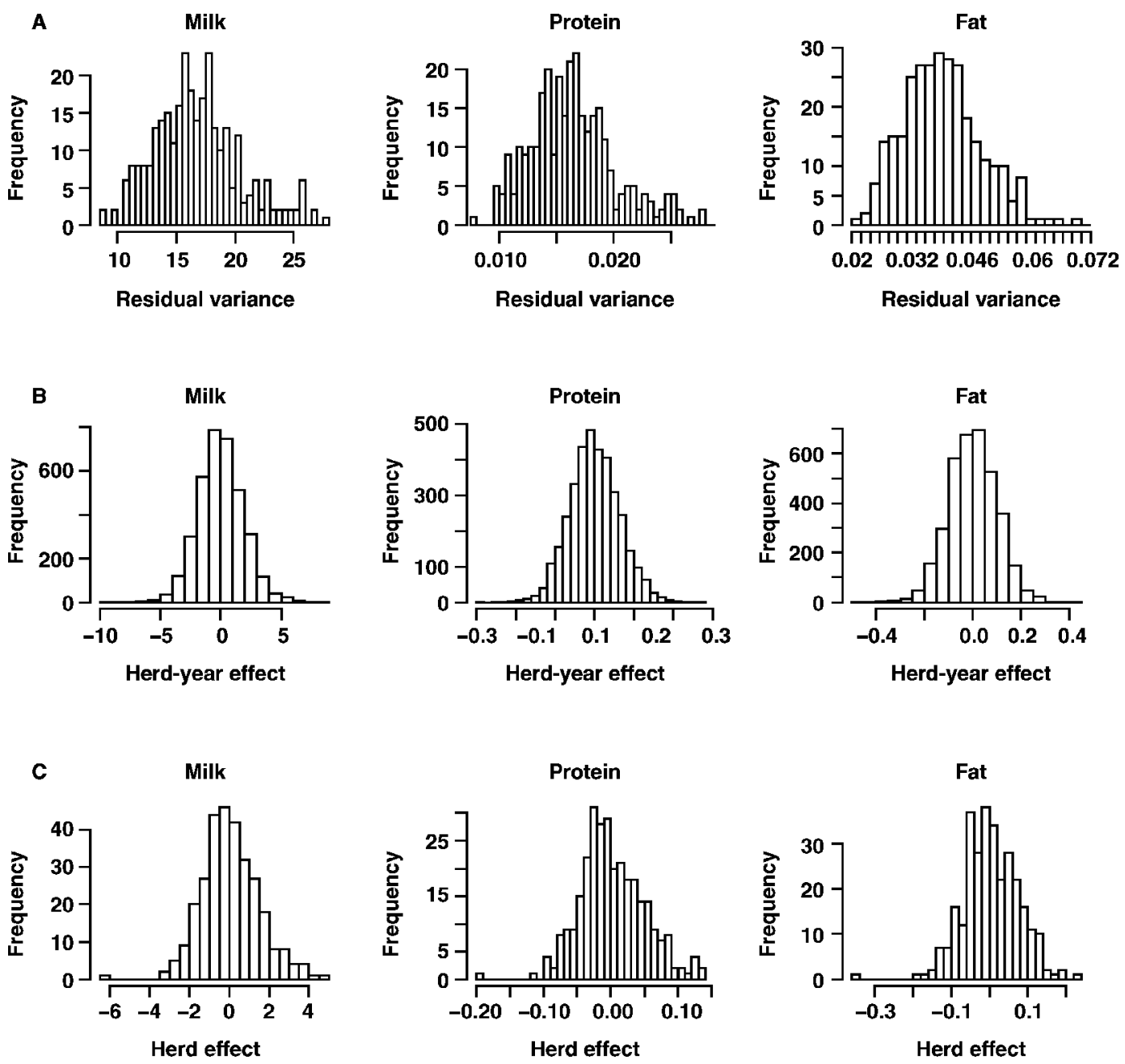

Figure 1. Distribution of posterior means of a) herd-specific residual variances, b) herd-year effects, and c) herd effects defined as averaged herd-year effects over years for each herd for milk, protein, and fat yield.

mated, but did not become negative. This is because with RNUCS the residual variance is kept fixed among environments, whereas the genetic variance can vary over herd-years. As a result, the variation in the residual variances is partly manifested in the genetic variance through overestimated genetic slopes (Strandberg, 2006).

In the current study, assuming a residual variance for each herd was supported by the data. When the number of observations in each herd is small, the alternative approach to account for heterogeneous residual variance is to classify herd-years into several environmental groups. The problem is that there is no satisfactory criterion to be used for grouping the environments in advance because the variation of residuals within herd-year is unknown. One possible solution is to allocate each herd-year into environmental groups dynami- cally in the Gibbs sampling process based on the variation of the estimated residuals.

\section{Residual Variances}

Histograms of Monte Carlo estimates of posterior means of residual (within herd) variances for milk, protein, and fat yield are shown in Figure 1a. The averages across herds were $16.60,0.016$, and 0.040 for milk, protein, and fat yield, respectively. The empirical correlation between posterior means of residual variances of milk and protein was 0.93 . The corresponding correlation coefficient between posterior means of residual variances of milk and fat yield was 0.71 , and between protein and fat yield was 0.76 . This indicates that environmental variability within herd is more similar for milk yield and protein yield, but less similar for milk 
Table 4. Estimated genetic level variance $\left(\sigma_{a_{0}}^{2}\right)$, covariance of genetic level and slope $\left(\sigma_{a_{0} f_{f}}\right)$, genetic slope variance $\left(\sigma_{a f}^{2}\right)$, additive genetic variance in the environments 1 standard deviation above $\left(\sigma_{a++}^{2}\right)$ and below $\left(\sigma_{a(-)}^{2}\right)$ the mean environmental effect, and the genetic correlations between these environments $\left(r_{a(-,+)}\right)^{1}$

\begin{tabular}{lcccccc}
\hline Item & $\sigma_{a_{0}}^{2}$ & $\sigma_{a_{0} a_{f}}$ & $\sigma_{a_{f}}^{2}$ & $\sigma_{a(-)}^{2}$ & $\sigma_{a(+)}^{2}$ & $r_{a(-,+)}$ \\
\hline Milk & $4.04(0.14)$ & $0.86(0.07)$ & $0.31(0.06)$ & $2.62(0.15)$ & $6.08(0.22)$ & $0.93(0.017)$ \\
Protein & $3.10(0.20)$ & $0.77(0.08)$ & $0.31(0.04)$ & $1.87(0.11)$ & $4.95(0.23)$ & $0.91(0.018)$ \\
Fat & $12.40(0.33)$ & $5.26(0.20)$ & $2.72(0.19)$ & $4.60(0.27)$ & $25.63(0.69)$ & $0.89(0.017)$ \\
\hline
\end{tabular}

${ }^{1}$ Variance components and their standard deviations for protein and fat yield have been multiplied by $10^{3}$. Numbers in parentheses are posterior standard deviations.

yield and fat yield and for protein yield and fat yield. Using RNUCS, the estimated residual variances for milk, protein, and fat yield were $16.63,0.016$, and 0.038 , respectively. It shows that by postulating a single residual variance in the reaction norm model, the residual variance in the mean environment is estimated.

A number of studies have implemented reaction norm sire-models with homogeneous residual variance (Kolmodin et al., 2002; Fikse et al., 2003). In the sire model one-quarter of the genetic variance is explained by the sire variance, and the remaining three-quarters of the genetic variance is contained in the residual variance (Falconer and MacKay, 1996). Therefore, when reaction norm models are applied for sires, residual variances should be modeled as heterogeneous across environments.

\section{Herd-year Effects}

Posterior means of variances of herd-year effects for milk, protein, and fat yield were 4.13, 0.0046, and 0.0107 , respectively. Figure $1 \mathrm{~b}$ displays the distribution of estimated herd-year effects. Herd effects, defined as the average of the estimated herd-year effects over years, are shown in Figure 1c. The correlation between posterior means of herd effects and of herd-specific residual variances was smaller than 0.10 for all traits studied. This suggests that heterogeneity of residual variances cannot be removed by a simple transformation of the data (Hayes et al., 2003).

In the present study, only data from herds with records from at least 30 first lactation cows per year were included. If small herds had lower management levels, the exclusion of small herds would result in somewhat of a decrease in the variation of environmental effects. This would not have an impact on the estimate of variance of slope because the slope is independent of the range of environmental effects if $\mathrm{G} \times \mathrm{E}$ has a linear reaction norm over all environments. However, the genetic correlation between extremely poor and extremely good environments could be slightly overestimated, and the extent of reranking could be somewhat underestimated because of a possible exclusion of the worst environments.

\section{Genetic Variance Components and Correlations}

Table 4 shows Monte Carlo estimates of posterior means of various genetic parameters, including the elements of the covariance matrix $\mathrm{G}\left(\sigma_{a_{0}}^{2}, \sigma_{a_{0} a_{f}}\right.$, and $\left.\sigma_{a_{f}}^{2}\right)$, the additive genetic variance (defined in equation [4]) in environments 1 standard deviation above and below the mean environmental effect $\left(\sigma_{a(+)}^{2}\right.$ and $\sigma_{a(-)}^{2}$, respectively), and the genetic correlation (defined in equation [6]) between these environments $\left(r_{a(-,+)}\right)$. The posterior distribution of the variance of the slope $\sigma_{a_{f}}^{2}$ was shifted away from zero for all traits under study, supporting the presence of $\mathrm{G} \times \mathrm{E}$. The ratio of interaction (slope) variance to the genetic level variance was largest for fat production and smallest for milk yield, indicating that the amount of $\mathrm{G} \times \mathrm{E}$ is highest in the former. Fat yield showed the lowest genetic correlation between environments, followed by protein and milk yield. The genetic correlation indicates the extent of reranking of genotypes across environments (Falconer, 1990). The magnitude of the genetic correlation in the present study indicates that there cannot be major reranking of genotypes in the different environments (Robertson, 1959). The rank correlations between breeding values at 5 th and 95th quantiles of the estimated environmental effects were respectively equal to $0.91,0.90$, and 0.76 for milk, protein, and fat yield. The correlations for milk and protein yield are high, and little reranking across extreme environments is expected. In the case of fat yield, high genetic variability in early lactation along with a high magnitude of $\mathrm{G} \times \mathrm{E}$ variance translates into variable response of genotypes to different environments and lower rank correlation across extremely different environments.

In this study, the additive genetic variance was always larger in the good environments than in the poor environments (Table 4, Figure 2). The proportional dif- 

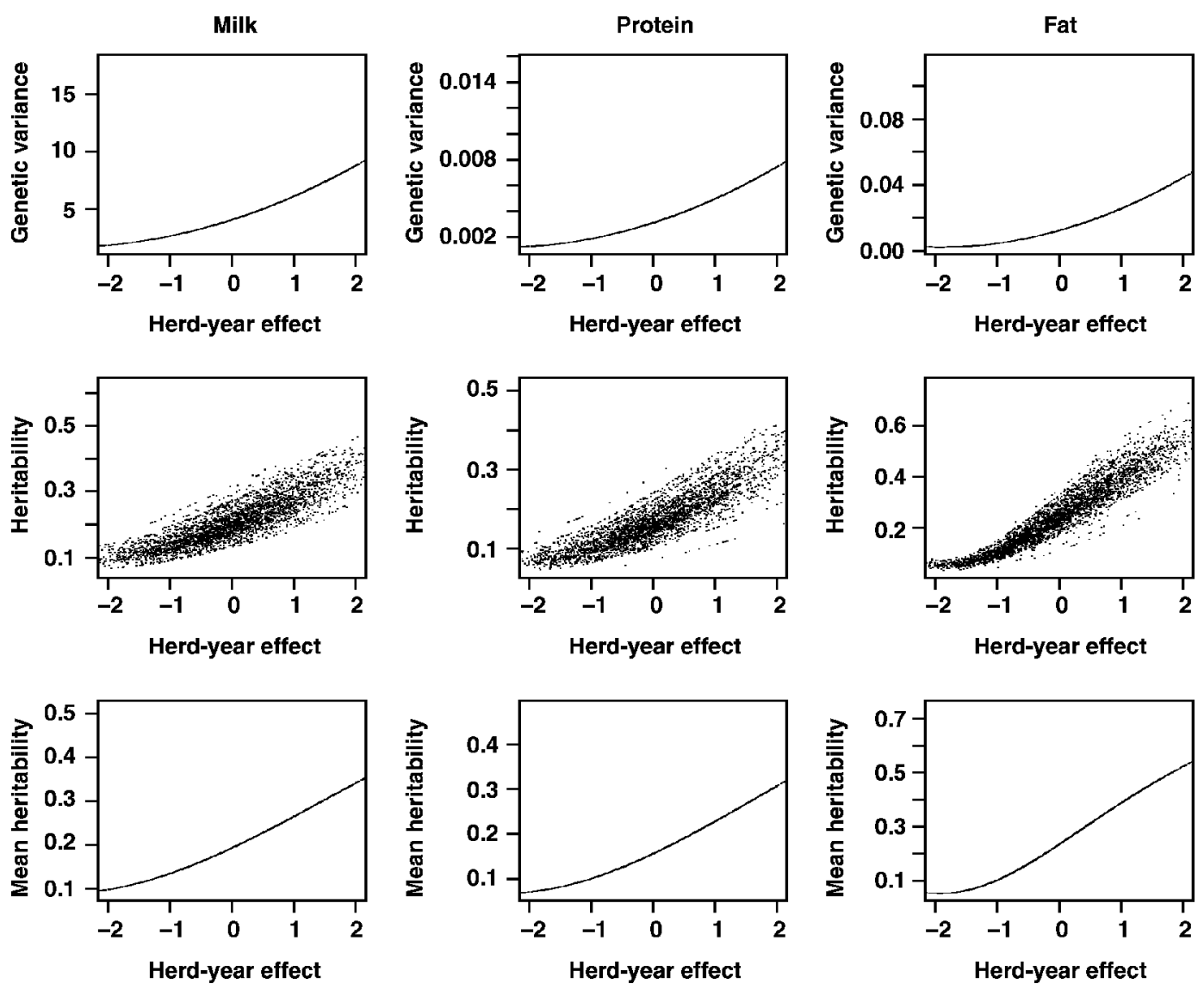

Figure 2. Plots of posterior means of genetic variances and heritabilities against standardized herd-year effects. Heritability (the middle row) was calculated using herd specific residual variance. Mean heritability (the bottom row) was calculated using mean residual variance averaged over herds.

ference in additive genetic variances across environments was largest for fat yield.

The ratios of (co)variance components for milk yield to (co)variance components for protein yield were $(\times 1,000) 1.3,1.1$, and 1.0 for $\sigma_{a_{0}}^{2}, \sigma_{a_{0} a_{f}}$, and $\sigma_{a_{f}}^{2}$, respectively. The corresponding ratios of milk to fat yield were $(\times 1,000) 0.33,0.16$, and 0.11 . The constant ratios of milk yield to protein yield suggest that the two traits have a similar reaction norm.

The maximum genetic variability of fat yield occurs during the first days of lactation (Swalve, 1995; de Roos et al., 2004). In the current study, the genetic level variance for fat yield was 4 times larger than the variance of genetic level for protein yield (Table 4). This variance determines the additive genetic variance in the mean environment (at $f=0$ ). Swalve (1995) detected the same result with first test-day records of first lactation Friesian cows from northern Germany, where the environmental conditions are similar to Denmark. In his study, additive genetic variances were slightly lower than the values in the present study.
If the aim of a breeding program is to obtain individuals that perform well across the whole range of the environmental gradient, then selection could be based on the (posterior mean of the) breeding values in the mean environment (at $f=0$ ). The Pearson correlation coefficients of breeding values in the mean environment and the breeding values from an additive genetic model without genetic effects for slope were $0.99,0.99$, and 0.97 , for milk, protein, and fat yield, respectively. The analogous Spearman's rank correlation coefficients were $0.98,0.98$, and 0.96 . The high correlations show that a simple additive genetic model is reasonable when the purpose is to rank animals for overall performance across a range of environments.

\section{Heritabilities}

Trajectories of heritabilities (defined in equation [5]) for milk, protein, and fat yield over environmental effects are displayed in Figure 2. The mean heritability shows the trajectory of heritability in a herd with aver- 
age residual variance that is approximately the mean of heritabilities in each environment. The plots in Figure 2 show that both heritability and variation of heritability between herd-years increased with increasing herdyear effects. The increase in variation of heritability between herd-years was largest for fat and protein yield. These results are in agreement with the study on protein yield by Calus et al. (2002) and on milk production traits by Hayes et al. (2003), who observed higher heritabilities in the "best" environments. On the other hand, Calus and Veerkamp (2003) did not find heterogeneity in heritability for milk production traits across environmental values defined as average protein production, although heterogeneous genetic variances were detected.

\section{CONCLUSIONS}

This study indicates that even in a small country like Denmark with rather standardized production environments, $\mathrm{G} \times \mathrm{E}$ can be detected. The degree of $\mathrm{G} \times \mathrm{E}$ for fat yield was larger than for milk yield and protein yield, whereas milk yield and protein yield had a similar reaction norm. Genetic variance and heritability increased with environmental values for all the three traits. However, the impact on reranking was shown to be rather limited, indicating that most of the $\mathrm{G} \times \mathrm{E}$ effect in this study was due to scale effects. In addition, the present study suggests that heterogeneous residual variances should be taken into consideration in the analysis of $\mathrm{G} \times \mathrm{E}$ using a reaction norm model to avoid the confounding between variation of genetic slopes and variation of environmental effects within the production system.

\section{ACKNOWLEDGMENTS}

The Ministry of Science, Research and Technology of Iran is acknowledged for financial support of M. M. Shariati. The authors wish to thank Mogens Sand $\emptyset$ Lund (Department of Genetics and Biotechnology, University of Aarhus, Denmark) and two referees for many helpful suggestions.

\section{REFERENCES}

Babot, D., J. L. Noguera, L. Alfonso, and J. Estany. 2003. Fixed or random contemporary groups in genetic evaluation for litter size in pigs using a single trait repeatability animal model J. Anim. Breed. Genet. 120:12-22.

Bundgaard, E., and S. Høj. 2000. Direct access to the cattle database with livestock registration. Annual Report 1999, National Committee in Danish Cattle Husbandry, Aarhus, Denmark.

Calus, M., P. Bijma, and R. Veerkamp. 2004. Effects of data structure on the estimation of covariance functions to describe genotype by environment interaction in a reaction norm model. Genet. Sel. Evol. 36:489-507.

Calus, M. P. L., A. F. Groen, and G. de Jong. 2002. Genotype $\times$ Environment interaction for protein yield in Dutch dairy cattle as quantified by different models. J. Dairy Sci. 85:3115-3123.

Calus, M. P. L., and R. F. Veerkamp. 2003. Estimation of environmental sensitivity of genetic merit for milk production traits using a random regression model. J. Dairy Sci. 86:3756-3764.

de Roos, A. P. W., A. G. F. Harbers, and G. de Jong. 2004. Random herd curves in a test-day model for milk, fat, and protein production of dairy cattle in the Netherlands. J. Dairy Sci. 87:2693-2701.

Falconer, D. S. 1990. Selection in different environments: Effects on environmental sensitivity (reaction norm) and on mean performance. Genet. Res. 56:57-70.

Falconer, D. S., and T. F. C. MacKay. 1996. Introduction to Quantitative Genetics. 4th ed. Longman Group, Essex, UK.

Fikse, W. F., R. Rekaya, and K. A. Weigel. 2003. Genotype × environment interaction for milk production in Guernsey cattle. J. Dairy Sci. 86:1821-1827.

Hayes, B. J., M. Carrick, P. Bowman, and M. E. Goddard. 2003. Genotype $\times$ environment interaction for milk production of daughters of Australian dairy sires from test-day records. J. Dairy Sci. 86:3736-3744.

Henderson, C. R. 1973. Sire evaluation and genetic trends. In Proceedings of the Animal Breeding and Genetics Symposium in Honor of Dr. J. L. Lush. Am. Soc. Anim. Sci. Champaign, IL.

Ibanez, M. A., M. J. Carabano, and R. Alenda. 1999. Identification of sources of heterogeneous residual and genetic variances in milk yield data from the Spanish Holstein-Friesian population and impact on genetic evaluation. Livest. Prod. Sci. 59:33-49.

Kolmodin, R., E. Strandberg, P. Madsen, J. Jensen, and H. Jorjani. 2002. Genotype by environment interaction in Nordic dairy cattle studied using reaction norms. Acta Agric. Scand. Anim. Sci. 52:11-24.

Lynch, M., and J. B. Walsh. 1998. Genetics and Analysis of Quantitative Traits. Sinauer Associates, Sunderland, MA.

Oseni, S., I. Misztal, S. Tsuruta, and R. Rekaya. 2004. Genetic components of days open under heat stress. J. Dairy Sci. 87:3022-3028.

Raffrenato, E., R. W. Blake, P. A. Oltenacu, J. Carvalheira, and G. Licitra. 2003. Genotype by environment interaction for yield and somatic cell score with alternative environmental definitions. J. Dairy Sci. 86:2470-2479.

Robertson, A. 1959. The sampling variance of the genetic correlation coefficient. Biometrics 15:469-485.

Short, T. H., R. W. Blake, R. L. Quass, and L. D. Van Vleck. 1990. Heterogeneous within-herd variance. 1. Genetic parameters for first and second lactation milk yields of grade Holstein cows. J. Dairy Sci. 73:3312-3320.

Sorensen, D., and D. Gianola. 2002. Likelihood, Bayesian and MCMC Methods in Quantitative Genetics. Springer-Verlag, New York, NY.

Spiegelhalter, D. J., N. G. Best, B. P. Carlin, and A. van der Linde. 2002. Bayesian measures of model complexity and fit. J. Roy. Stat. Soc. B 64:583-639.

Strandberg, E. 2006. Analysis of genotype by environment interaction using random regression models. Proc. 8th World Congr. Genet. Appl. Livest. Prod., Belo Horizonte, Brasil. CD-ROM Communication No. 25-05.

Su, G., P. Madsen, M. S. Lund, D. Sorensen, I. R. Korsgaard, and J. Jensen. 2006. Bayesian analysis of the reaction norm model with unknown covariates. J. Anim. Sci. 84:1651-1657.

Swalve, H. H. 1995. The effect of test-day models on the estimation of genetic parameters and breeding values for dairy yield traits. J. Dairy Sci. 78:929-938.

Ugarte, E., R. Alenda, and M. J. Carabano. 1992. Fixed or random contemporary groups in genetic evaluations. J. Dairy Sci. 75:269-278

Visscher, P. M., and M. E. Goddard. 1993. Fixed and random contemporary groups. J. Dairy Sci. 76:1444-1454. 